\title{
Ocupar com o cinema - escrita da história das lutas urbanas em Ressurgentes - um filme de ação direta
}

Vinícius Andrade de Oliveira

Resumo: $\mathrm{O}$ artigo analisa a retomada de arquivos de cerca de dez anos de lutas urbanas conduzidas por movimentos autônomos de Brasília e sua articulação através da montagem no documentário Ressurgentes - um filme de ação direta. Interessa-nos apontar como a associação desses materiais heterogêneos aos testemunhos no presente dos próprios militantes engendram uma peculiar escrita da história dos problemas urbanos vividos em Brasília na última década e suas relações possíveis com acontecimentos comuns a outras cidades, como as Jornadas de Junho de 2013.

Palavras-chave: retomada; arquivos; história; documentário; Ressurgentes.

Abstract: Occupy with cinema - writing the history of urban struggles in Ressurgentes - um filme de ação direta. The article analyses the retaking of archives of about 10 years of urban struggles conducted by autonomous movements of Brasília and its articulation through the editing in the documentary Ressurgentes - um filme de ação direta. We are interested in pointing out how the association of these heterogeneous archives with the testimonies of militants beget a peculiar writing of the history of urban problems experienced in Brasilia in the last decade and their possible relations to common events to other cities, such as June's 2013 manifestations.

Keywords: retaking; archives; history; documentary; Ressurgentes.

Ressurgentes - um filme de ação direta (Dácia Ibiapina, DF, 2014) tem início no "interior" de alguns acontecimentos, especificamente em meio à ocupação da Câmara Legislativa do Distrito Federal, em 2009, por manifestantes que pediam o impeachment do então governador distrital José Roberto Arruda, àquela altura integrante 
do Partido Democratas (DEM). A equipe de filmagem capta de um ponto de vista privilegiado o momento preciso em que os manifestantes precipitam a entrada na casa, como se a câmera fosse mais um "sujeito" entre os que conduziam a iniciativa. O registro desse intenso embate, que antes de compor a abertura do filme funcionou como impulso inicial para a realização do projeto, surgido sem um roteiro pré-concebido, só se tornou possível, no entanto, em razão da emergência pública de outras imagens.

Meses antes da ocupação da Câmara, circularam na mídia local imagens feitas por Durval Barbosa, ex-secretário de Relações Institucionais do Distrito Federal, que documentavam um esquema de corrupção envolvendo o governador, membros do governo próximos a ele e alguns proprietários de meios de comunicação do Distrito Federal. Essas imagens, captadas por uma câmera escondida, fizeram explodir a polêmica que motivou a equipe da realizadora Dácia Ibiapina a interromper as gravações de outro filme e se voltar para o desenrolar dos acontecimentos políticos que tomavam os noticiários da cidade e mobilizavam a atenção da população'.

Diferentemente do que o início do filme pode sugerir, não é, contudo, apenas o registro de manifestações e ocupações que Ressurgentes realiza. A singularidade de sua escritura fílmica se revela na particular alternância e articulação criativa entre materiais de arquivo de cenas de embate entre militantes (de movimentos autônomos de Brasília) e representantes do poder público, grupos econômicos e forças policiais, materiais de arquivo da televisão do período em que esses embates ocorreram e testemunhos no presente dos militantes que aparecem em ação nas imagens de arquivo. É a partir desses dois procedimentos - retomada dos arquivos e testemunho - e das relações entre eles tecida que devemos pensar a escrita da história dos conflitos urbanos recentes engendrada pelo filme em sua narrativa.

Utilizamos a noção de retomada das imagens de arquivo tal como formulada por Sylvie Lindeperg (2010; 2013). Para a autora, a partir de um primeiro gesto analítico de "(...) seguir o caminho das imagens", ou seja, "(...) restituir-lhes a iniciativa, prestando atenção aos sinais instáveis de que elas são depositárias" (LINDEPERG, 2013, pág. 10), deve-se observar em seguida as incidências e o "imbricamento" dos olhares (de quem filma e quem é filmado) no contexto de reutilização das imagens e os agenciamentos com outras imagens produzidas através da montagem. Sem jamais deixar de considerar os contornos sensíveis de uma imagem e remetê-la ao fora de campo envolvido na sua produção, deve-se levar em conta os significados que adquire em seu novo contexto de uso.

No caso de Ressurgentes - um filme de ação direta são alternadas imagens produzidas pelos próprios militantes (com objetivo inicial de produzir memória sobre os movimentos, denunciar abusos policiais, defender-se juridicamente de possíveis acusações), imagens das televisões (retratando publicamente os acontecimentos políticos) e imagens feitas pela equipe de realização do filme, que acompanhou parte do grupo de manifestantes

1 Informações colhidas em entrevista realizada com a diretora em novembro de 2015. 
presentes na ocupação da Câmara Distrital de 2009 até a finalização das filmagens em 2013. Os testemunhos colhidos são montados a partir da retomada desses três grupos diferentes de imagem.

O contexto histórico no qual o filme se situa aponta para a emergência de um conjunto expressivo de filmes, realizados muitas vezes a partir da colaboração entre cineastas e movimentos sociais, que se notabilizam por, simultaneamente, participarem das e registrarem as disputas pela retomada do espaço urbano. Filmes que, de dentro dos conflitos e com os meios cinematográficos, produzem olhares que lançam tais conflitos num quadro social mais amplo. Esse quadro, por sua vez, envolve uma complexa confluência de fatores, que vão desde o aprofundamento da crise urbana nas cidades brasileiras até a emergência de novos movimentos de luta social (MARICATO, 2014), passando pela acentuação dos impactos do capitalismo financeirizado na vida dos cidadãos (ROLNIK, 2015).

No presente texto, buscamos mostrar no documentário analisado como a associação entre os arquivos selecionados e os testemunhos dos militantes colabora com a elaboração pelo filme de uma visão de história ancorada na centralidade do confronto entre visões antagônicas de mundo, traço que vai aparecer não somente na relação entre arquivos e testemunhos, mas também como princípio de montagem que norteia todo o filme. Nesse sentido, procuramos também apontar que tipo de leitura ou "legibilidade" (HUBERMAN, 2012, pág. 155) essa montagem sugere para as lutas retratadas no decorrer do documentário, incluindo aí a sequência final em que as Jornadas de Junho de 2013, marco nas transformações históricas mencionadas acima, são abordadas.

\section{Dos arquivos aos testemunhos no presente}

O primeiro núcleo de acontecimentos de Ressurgentes é o que trata do movimento "Fora Arruda", nome como a mobilização em favor do impedimento do ex-governador foi batizada. Depois do já mencionado registro da entrada dos manifestantes para o interior da Câmara Legislativa, durante cinco dias a equipe de filmagem parece "ocupar" a casa junto com eles: sempre próxima, registra os cânticos de luta, os gritos e cartazes de protesto, as assembleias de discussão, a mobilização, as conversas, os olhares apreensivos de funcionários da Câmara e de jornalistas dos meios de comunicação, posicionados "ao redor" da área ocupada (e da própria equipe), e a interação/reação que os ocupantes mantiveram com as notícias (judiciais, midiáticas, políticas) que chegavam do exterior.

A iminência do cumprimento do mandado de reintegração de posse da Câmara pela polícia militar desdobra uma assembleia de discussão entre os manifestantes sobre a continuidade ou não da ocupação e motiva a chegada de representantes do poder público para uma negociação cujo objetivo consistia em conseguir a saída voluntária e pacífica dos ocupantes. Em meio às negociações, a notícia de que a reintegração não seria mais realizada naquele dia é recebida pelos manifestantes, o que dá início a uma comemoração efusiva. 
Eles entoam: "Arruda vai ganhar/uma passagem pra sair desse lugar/ Não é de carro, nem de trem, nem de avião/ é algemado num camburão/ eita Arruda ladrão!".

São inseridas aí imagens de arquivo do escândalo de corrupção gravadas por Durval Barbosa, ex-secretário de Relações Institucionais do governo do Distrito Federal (GDF). A marchinha adaptada pelos ocupantes é usada como trilha para as imagens de arquivo produzidas pela câmera oculta usada pelo ex-secretário. Cântico de luta e imagens de arquivo são associados pela montagem para denunciar o caráter ilícito das ações da cúpula do GDF e o próprio arquivo é manipulado com o mesmo intuito: vemos a língua pra fora de Alcyr Collaço, dono do jornal "Tribuna do Brasil", sendo repetida (ao modo de um scratch de disco, um arranhão), bem como a imagem de Arruda, recebendo um insert de quadro ampliado. Trata-se de "ver melhor" ou "de perto" o recebimento do dinheiro do esquema de corrupção denunciado, procedimentos reservados para um notório opositor ou "inimigo" 2 .

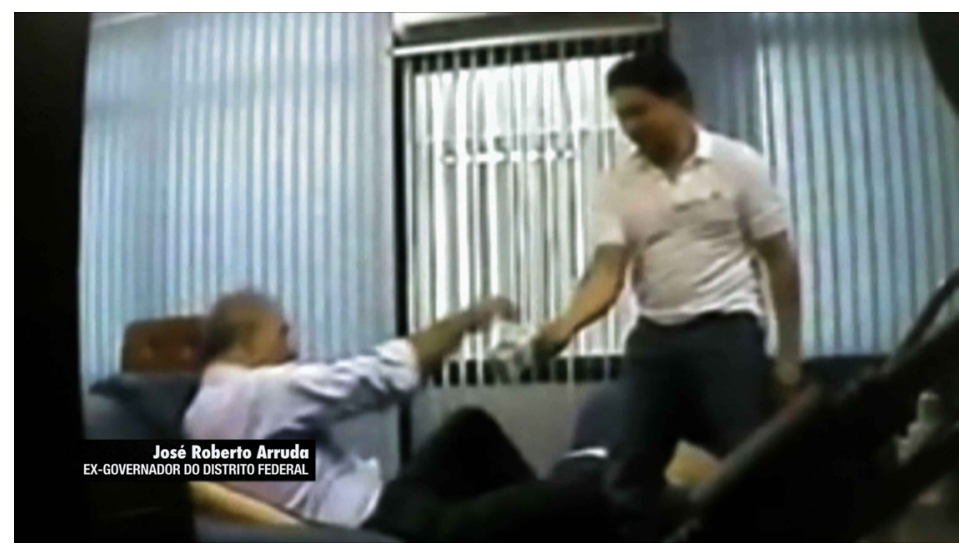

Fig.1.magem da participação do ex-governador do Distrito Federal, José Roberto Arruda, em esquema de corrupção deflagrado em 2009, retomada em Ressurgentes

Mais imagens de arquivo são inseridas nesse momento, dessa vez da reportagem da TV Globo de Brasília, relatando a "saída" dos manifestantes da Câmara Legislativa. A montagem de diferentes trechos de imagem e áudio da reportagem revelam uma contradição entre a locução conduzida pelo jornalista e a imagem que documenta a ocasião, entre o que é dito e o que vemos. Enquanto o repórter diz: "Quatro horas depois da chegada da polícia, finalmente houve um acordo para que os manifestantes que ocupavam o prédio deixassem o local", vemos imagens dos manifestantes sendo retirados à força pelos policiais. Alguns deles são carregados por quatro ou cinco policiais ao mesmo tempo, tendo braços e pernas imobilizados, indicando uma resolução exatamente oposta a um acordo.

Essa é a deixa para a abordagem dos acontecimentos pelo testemunho, no presente, de um dos ocupantes da Câmara, Gabriel Soares, antropólogo e militante dos movimentos

2 Referimo-nos aqui à ideia de inimigo tal como trabalhada por Jean-Louis Comolli em seu texto "Como filmar o inimigo?" (2008), no qual aponta o cinema documentário como um "lugar" propício para dar corpo aos motivos de pensamento de um adversário político de modo a combatê-lo melhor. 
autônomos $^{3}$ de Brasília. Ele não só evidencia a contradição entre proposta de acordo e ação violenta da polícia, que a montagem das imagens de arquivo da TV havia exposto, como articula essas imagens a um sentido geral das práticas de ocupação. Seu testemunho também conecta as ações pontuais de ocupação a processos históricos mais extensos vividos no Distrito Federal, como a retirada de moradores pobres (ex-operários da construção de Brasília) do Plano Piloto para as chamadas cidades satélite, processo que culminou, dentre outros efeitos, na criação e ocupação da Ceilândia.

A reflexão de Gabriel, bem como a de Artuzin, mestre em ciência política e militante dos movimentos autônomos de Brasília que fala na sequência sobre os embates urbanos recentes e seus sentidos políticos e históricos, permitem ao filme a passagem para mais imagens de arquivo da repressão policial ao movimento "Fora Arruda", dessa vez nas ruas de Brasília, ainda em dezembro de 2009. As articulações entre a mise-en-scène expressa nas imagens de arquivo das lutas, registradas pelos militantes, e os seus próprios testemunhos no presente, a partir do qual elaboram uma perspectiva sobre os acontecimentos filmados, se distancia em sua forma do que vemos em um conjunto significativo de filmes documentais brasileiros que tratam de manifestações, sobretudo os que se concentram nas Jornadas de Junho de 2013.

Seja em Por uma vida sem catracas (Carlos Pronzato, SP, 2013), em Com vandalismo (Coletivo Nigéria, CE, 2013) ou em Junho (João Wainer, SP, 2014), para ficarmos em três exemplos, a maior parte das cenas de embate entre manifestantes e forças policiais incorporadas aos filmes são montadas como uma espécie de videoclipe, em que cada plano tem duração reduzida e o teor de energia das cenas é enfatizado por uma trilha rock'n roll, ao modo de um filme de ação, ou como meras ilustrações dos depoimentos de militantes ou especialistas. Eventualmente, essas duas operações coincidem, o que, nos parece, retira a possibilidade de pensarmos mais detidamente sobre as razões desses conflitos, seus precedentes, os possíveis desdobramentos.

No documentário de Dácia Ibiapina privilegia-se, pelo contrário, as mise-enscènes próprias às cenas de embate entre militantes e seus opositores, sensíveis no trabalho da câmera ao assumir o ponto de vista espacial dos militantes (quando não são utilizadas, efetivamente, imagens feitas por militantes), no gesto de dar atenção especial à movimentação de seus corpos pelo espaço e ao desempenho de sua palavra no enfrentamento da palavra dos representantes do poder. Além disso, é importante notar a opção dos realizadores de não tentar simplesmente "iluminar" os materiais de arquivo pelos depoimentos, mas expandir os significados em jogo nas imagens pela associação com outras imagens e depoimentos, tornando-os mais complexos.

Esses testemunhos dados pelos militantes parecem funcionar, por sua vez, no duplo sentido da noção de testemunho, como trabalhada por Márcio Seligmann-Silva (2010):

3 Movimentos autônomos são movimentos apartidários, de estrutura horizontal e não dependente de financiamentos advindos de qualquer instituição. 
tanto proximidade e enraizamento na experiência (podemos ver nas imagens de arquivo as vivências a partir das quais testemunham), como distanciamento reflexivo, capacidade de julgar, discernir. O momento do testemunho apresenta-se como instância de trânsito e troca entre os afetos em fluxo na atuação dos personagens no passado e uma elaboração crítica dos acontecimentos vividos no presente, articulando as cenas de enfrentamento com as cenas de escuta daqueles que participaram dos embates.

Em texto recente sobre o filme, Amaranta Cesar aponta justamente para esse importante jogo entre tomadas, retomadas e testemunhos:

a montagem em Ressurgentes opera para relacionar os corpos nos espaços com a reconstituição do pensamento onde se projetam e para onde se prolongam as disputas materiais e simbólicas em jogo. No equilíbrio delicado entre pensamento e ação, a montagem trabalha para evitar a cisão (que seria desastrada) entre essas duas dimensões e as temporalidades que nelas estão implicadas o presente do engajamento e o passado da reconstituição da recente história. A ação dos corpos encarna os mundos desejáveis que as falas elaboram, mas a elaboração do pensamento e do imaginário de luta acontece nos dois tempos o mais evidente sinal dessa passagem se dá pelos próprios corpos das testemunhas que vemos não apenas nos clássicos planos de entrevista, mas em ação nas imagens das ocupações e manifestações. (CESAR, 2015, pág. 110)

Tais operações mencionadas pela autora se mostram igualmente complexas e relevantes no momento posterior às falas de Gabriel Soares e Artuzin, na relação criada entre as imagens de arquivo da TV Globo de Brasília sobre a prisão de José Roberto Arruda e a fala de Rafa Kaoos que a precede.

Embora possamos notar que, na associação entre o testemunho do militante e o arquivo da TV, este último funciona como uma espécie de atestação factual, pública (trata-se de uma reportagem exibida no noticiário de maior audiência da região), ao longo da primeira parte do documentário vemos como que o inverso: os testemunhos operam como contra-discursos daquilo que diz a televisão e os outros arquivos produzidos por militantes denunciam a violência policial que a televisão deliberadamente ignora. A palavra dos militantes não é construída no filme como dependente da validação dos arquivos televisivos, ela aparece com valor próprio, ao mesmo tempo singular e contestatório.

À reportagem de TV que informa a prisão de José Roberto Arruda se seguem cenas do que parece ser o carnaval de Brasília e testemunhos de Izabele Pimenta, estudante de ciências sociais e também militante dos movimentos autônomos no DF, e Gabriel Soares, mas nos parece que é a fala de Cled, na sequência delas, que reverbera de modo mais contundente na própria forma do filme. Ele recusa uma concepção da História baseada no progresso e afirma que ela sempre foi e sempre será fruto de uma relação de forças, de um jogo de disputas e conflitos: em suas palavras, uma "queda de braços". 


\section{Uma história das lutas}

No livro "Imagens apesar de tudo", Georges Didi-Huberman apresenta uma visada sobre a montagem cinematográfica especialmente útil à nossa análise. Para o autor, o processo de montagem parte de uma dupla consciência. Se as imagens de um acontecimento não podem ser desprezadas por serem "apenas imagens", nem podem dar conta de tudo (no sentido de esgotar os significados do que mostram), é possível, diante dessa característica singular, montar imagens para produzir conhecimento acerca de um processo histórico. Montar para melhor ver o que já não pode ser totalmente visível: montar, associar, ajuntar, relacionar, conjugar para melhor visar um fenômeno, para lhe conceder visibilidade.

A montagem é o que permite às imagens um papel, ao mesmo tempo, estético e epistemológico: ao passo que faz essas imagens participarem da própria constituição do visível, também nos faz acessar formas de conhecimento histórico sobre os acontecimentos que elas retratam. Afirma Didi-Huberman:

a montagem só é válida quando não se apressa a concluir ou enclausurar: quando abre e complexifica nossa compreensão da história, e não quando a esquematiza abusivamente. Quando nos permite aceder às singularidades do tempo e, por conseguinte, à sua multiplicidade essencial (DIDI-HUBERMAN, 2012, pág. 156).

Na segunda parte de Ressurgentes, em torno do Santuário dos Pajés ${ }^{4}$, região localizada no setor Noroeste de Brasília e habitada por povos indígenas há muitas gerações, o traço que singulariza as operações de montagem, a nosso ver, é precisamente a explicitação das contradições em jogo nos acontecimentos filmados, aludida na concepção de História como "queda de braços" expressa por Cled.

Se os depoimentos anteriores (ainda tratando do "Fora Arruda") versavam sobre a incompatibilidade de pensamento e ação entre militantes e Estado, as primeiras imagens acerca da questão do Santuário dos Pajés (datadas de 2008, um ano antes do movimento pelo impedimento do governador) mostram representantes do Estado apresentando-se como "irmãos" de índios e militantes, capazes de fazer um "acordo" comum aos interesses de ambas as partes. Os testemunhos anteriores e essas imagens "chocam-se" mutuamente. Ressurgentes tomará um lado no antagonismo explicitado pela montagem, que será o de indígenas e militantes, por isso se empenhará em desmontar as aporias contidas nas palavras e ações dos agentes do Estado, da polícia e dos grupos econômicos.

Contudo, embora "tome" um lado, Ressurgentes não convoca ou "apela" para uma adesão irrefletida às causas que os militantes defendem. O filme recusa explicações unificadoras e consensuais. Não há narração que determine trilhas de interpretação,

4 Os indígenas moradores do Santuário dos Pajés eram liderados, no momento registrado no filme, pelo Pajé Santxiê, da etnia Tapuya Fulni-ô. Em apoio aos índios moradores do local foi formado um movimento chamado

"Santuário não se move", composto também por militantes que integravam movimentos autônomos de Brasília. 
nem letreiros explicativos, tampouco uma separação clara e rígida entre as partes de modo a simplificar o entendimento. O espectador é convidado a entender as razões dos conflitos, a ter acesso a visões que a mídia, o governo ou as empresas não apresentaram, e a formular, em alguma medida e por si mesmo, suas compreensões.

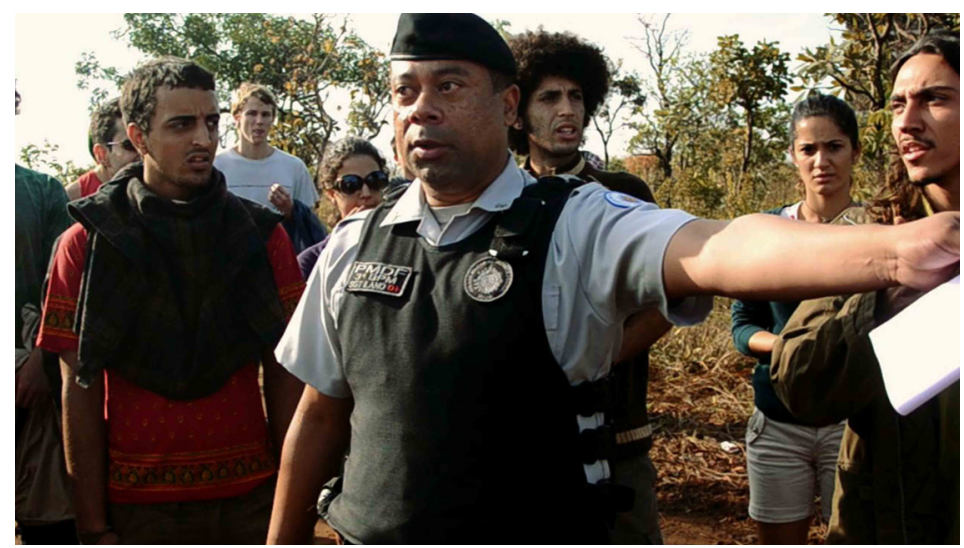

Fig.2. Sargento da Polícia Militar do Distrito Federal tenta "mediar" discussão entre defensores do Santuário dos Pajés e funcionários da empresa responsável pelo empreendimento no Setor Noroeste.

Tais características ficam bastante claras na segunda metade do documentário. O tema das políticas estudantis pontua, pelos testemunhos, o debate sobre a trajetória de militância dos entrevistados e os acontecimentos que motivaram suas entradas nos movimentos autônomos de Brasília. Um passado comum os une: a participação na mobilização contra o aumento da tarifa de transporte público realizado na Rodoviária de Brasília em 2005. Foi ali que muitos deles se conheceram, fizeram amizade e passaram a atuar juntos nas lutas urbanas (Movimento Passe Livre, Fora Arruda, Santuário não se move, Marcha das Vadias).

Acontecimento mais antigo em termos temporais, a mobilização na Rodoviária em 2005 é trabalhada apenas no final do filme, embaralhando ainda mais a sua cronologia. O vai-e-vem no tempo, pelo jogo entre arquivos, encontra seu recuo mais radical, justamente quando, em tese, nos encaminhamos cada vez mais para o presente. Ao perigo de uma linearidade que encerra o passado em algum lugar distante do tempo atual e encampa uma visão da história como evolução e progresso, Ressurgentes responde recusando uma progressão natural dos acontecimentos e articulando os fatos aparentemente mais distantes em termos temporais. A atualidade e os problemas de 2005, longe de restritos ao passado, podem assim ser reabertos no presente, sendo reelaborados no filme através da abordagem das lutas que se seguiram desde então.

Curioso notar que, enquanto em Brasília, contradições de uma cidade nova (Joaquim Pedro de Andrade, 1967), filme fundamental para compreendermos os problemas surgidos na própria gênese da cidade de Brasília, a Rodoviária constitui o ponto de virada narrativo 
do documentário a partir do qual se apresenta o outro lado de Brasília (o dos "excluídos" do Plano Piloto), em Ressurgentes a Rodoviária do DF constitui também um marco, mas dessa vez para indicar os desdobramentos das lutas e uma aglutinação de sujeitos. Esses sujeitos, mais tarde, reunidos em movimentos autônomos, irão questionar todo o histórico de problemas sociais vividos na cidade, reconectando as lutas aos problemas da origem da cidade. Bem, aqui não se trata mais apenas da retomada dos arquivos, mas do uso de uma imagem "símbolo", a Rodoviária, que aporta em si mesma, a partir de sua incorporação, sentidos históricos para as lutas atuais.

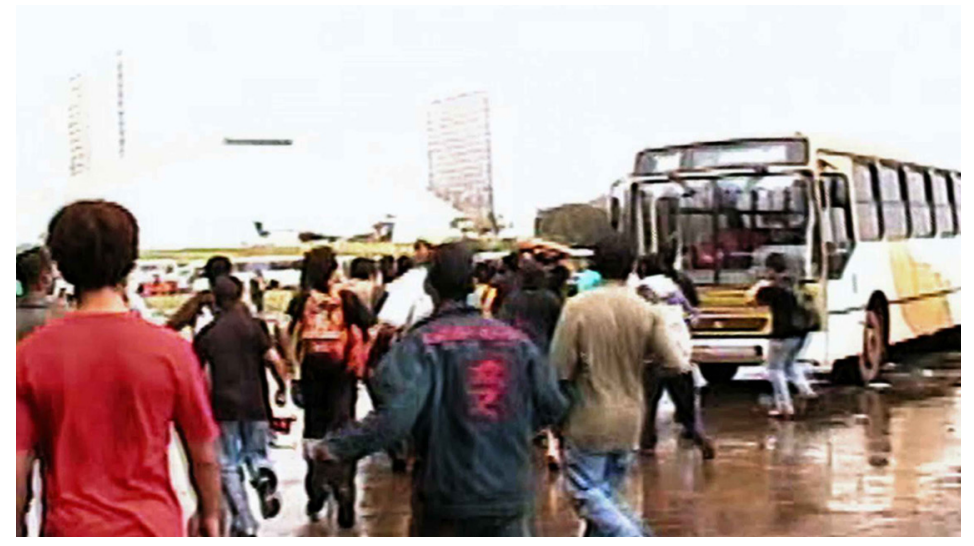

Fig.3.Imagem utilizada no filme do arquivo dos militantes da histórica mobilização contra o aumento da tarifa realizada em 2006 na rodoviária de Brasília.

Se apenas com a incorporação das imagens de arquivo do protesto na rodoviária em 2005 (quase dez anos antes do ano de gravação dos depoimentos para o filme) é que chegamos nas imagens das Jornadas de Junho de 2013 (que, sabemos, começaram em São Paulo justamente com um grande ato contra o aumento da tarifa de transporte convocado pelo Movimento Passe Livre) é porque o filme toma como fundamental a tarefa de compreendermos o momento histórico de emergência da pauta da tarifa zero (e seus desdobramentos) para que comecemos a compreender devidamente parte importante do fenômeno das manifestações e reivindicações de Junho. Não é senão pela via de uma posta em perspectiva das lutas urbanas do passado (ainda que recente) que o documentário propõe uma compreensão do presente. É através da rememoração da trajetória das vidas em luta, de um entrelaçamento com elas, que são construídas as coordenadas de aproximação dos dilemas vividos hoje.

É por isso que em Ressurgentes não há nem uma cronologia rígida de acontecimentos, nem separações marcadas entre a abordagem de uma luta e outra. Trata-se de propor uma narrativa que conecta um conflito ao outro sem, no entanto, reduzir um pela ou na explicação do outro. Trata-se de propor uma continuidade entre as lutas, que não significa 
que elas mantêm uma relação de causa e efeito, mas que uma contribui e favorece a emergência da outra. As Jornadas de Junho de 2013 se tornam, ao mesmo tempo, final e começo, ou seja, um ponto numa história de lutas mais ampla que as atravessa e ultrapassa.

Essa "legibilidade" (HUBERMAN, 2012, pág. 155) elaborada na escritura do filme enfrenta assim os jargões simplificadores que invadiram os meios de comunicação tradicionais nas manifestações de junho de 2013: “(...) a causa deve ser a ausência de causa", nas palavras de Arnaldo Jabor ${ }^{5}$, "Milhares vão às ruas 'contra tudo' (...)", uma das manchetes da Folha de São Paulo ${ }^{6}$. Mesmo em alguns órgãos da mídia internacional, um discurso semelhante se registrava, como no editorial do jornal francês "Le point", que dizia que as manifestações "(...) ecoaram como um trovão em céu aparentemente sereno" (apud ROLNIK, 2015, pág. 372). Vimos numa sorte variada de notícias uma espécie de lugar comum que poderia ser resumido nas seguintes ideias: as manifestações surgiram "de repente" (ou seja, não tiveram causa determinável) e as pessoas que as produziram apareceram "do nada" (provinham de um lugar desconhecido e sua indignação explodiu de modo imprevisto).

Para o documentário de Dácia Ibiapina trata-se exatamente de tentar descontruir essa "confusão": mostrar que a emergência das manifestações possuiu causas concretas e localizáveis (o aumento da tarifa, por exemplo) e mostrar que, se os grupos e sujeitos que desdobraram o início das manifestações não faziam parte de instituições ou movimentos historicamente conhecidos (como partidos políticos ou sindicatos de trabalhadores), nos cabe conhecer sua história de luta e entender que já há algum tempo fomentam uma cultura da "ação direta" como método e objetivo de intervenção política nos rumos da cidade; entender que o impulso para as manifestações não surge de uma indignação sem fundamento, mas de um empenho dos movimentos de luta gestados na última década em dar respostas renovadas aos desafios de uma atuação política capaz de enfrentar os graves problemas vividos nos centros urbanos brasileiros.

Alternar passado e presente de um conjunto ainda pouco conhecido de lutas urbanas significa, portanto, em Ressurgentes - um filme de ação direta, alternar também ação e reflexão, ou, mais precisamente, resulta em criar zonas de contiguidade entre essas duas dimensões. Isso revela uma escritura não apenas solidária às novas formas de atuação política postas em cena por esses movimentos, mas, sobretudo, portadora dessas formas em seus procedimentos fílmicos. Já não se trata mais de trabalhar com o dualismo teoriaprática, ou conscientização-ação, como fizeram gerações anteriores, para as quais a ação política era necessariamente precedida por um alinhamento ideológico comum, de cunho mais teórico, mas de "prefigurar" ${ }^{7}$ os objetivos de uma luta no próprio ato de lutar,

5 O comentário que inclui essa frase foi feito durante o "Jornal Nacional" do dia 15 de junho de 2013.

6 A manchete completa dizia "Milhares vão às ruas 'contra tudo'; grupos atingem palácios" e foi publicada pelo jornal no dia 17 de junho de 2013.

7 Utilizamos aqui a expressão de Pablo Ortellado no II Colóquio Cidades: experimentações sociais e criatividade política, realizado em São Paulo entre os dias 17 e 19 de maio de 2016. 
de "antecipar" o mundo desejado através da adoção de estratégias de luta potencialmente identificadas com o que se sonha para esse futuro coletivo.

\section{Intervir e lembrar}

Tomando a elaboração histórica realizada em Ressurgentes como referência, é sintomático notar que em alguns importantes filmes que abordam exclusivamente as Jornadas de Junho de 2013 (documentando o dia-a-dia das manifestações) - a exemplo de Com vandalismo (Coletivo Nigéria, CE, 2013) e Junho (João Wainer, SP, 2014) -, a proposta de dedicação integral ao presente dos acontecimentos de rua parece fazer escapar a uma compreensão mais profunda sobre tais acontecimentos. Ainda que, eventualmente, as cenas que os retratam sejam acompanhadas de entrevistas de caráter analítico, a extrema concentração no presente não tem garantido a esses filmes um acesso direto e desimpedido a uma explicação dos eventos, pelo contrário: parece bloquear uma relação sua com o passado, fazendo esse presente ficar sem passado e o passado das lutas desaparecer num futuro que o desconhece.

Sem configurar-se exatamente como um gesto de escrita da história (nesse caso, dos embates urbanos em Brasília) de todo original ou inédito, Ressurgentes se aproxima de obras contemporâneas que se equilibram entre as determinações concretas de uma luta específica e a elaboração de uma visada histórica mais cuidadosa sobre um conjunto de problemas. De um lado, uma postura de intervenção, realizada sob o signo da urgência; uma inscrição mais imediata no presente, sensível cinematograficamente em forças que incidem sobre o plano - a câmera se tornando escudo, a profundidade de campo sendo a distância segura para a barreira policial, como observa Amaranta César ${ }^{8}$. De outro, um olhar que busca algum distanciamento dos eventos, aposta no trabalho com os arquivos, na capacidade de rememoração das experiências e se materializa, sobretudo, através de operações não-lineares de montagem.

Assim como em Ressurgentes, encontramos tal modulação que regula medidas de relação com diferentes tempos históricos também em filmes como Martírio (Vincent Carelli, 2016) e Na missão, com Kadu (Aiano Benfica, Kadu Freitas e Pedro Maio de Brito, 2016). Tais filmes se diferenciam por um variado conjunto de características, que vão da temática central à escala de acontecimentos históricos abordados, passando, inclusive, pelos diferentes gestos criativos de montagem que articulam (aproximar, ligar e relacionar ou distanciar, romper e confrontar). Contudo, devemos notar que é através de procedimentos que jamais dissociam os diferentes tempos históricos, que atuam sempre no sentido de aprofundar e multiplicar suas relações, que reside o terreno comum a partir do qual podemos pensá-los.

8 Observações feitas pela pesquisadora no IV Colóquio Cinema, Estética e Política, realizado nos dias 24, 25 e

26 de junho de 2015, em Belo Horizonte. 
Assim, no já mencionado contexto de início da presente década, de emergência de um conjunto notável de filmes que se engajam e representam as disputas pela retomada do espaço urbano, podemos observar que as experiências que parecem melhor dar conta da complexidade da experiência social brasileira dos últimos anos passam por uma inscrição no presente dos acontecimentos políticos que não se desacompanha em momento algum de uma posta em perspectiva da história, conjugando - sem jamais opor - atos práticos de engajamento com estratégias narrativas de lembrança do passado. O desafio está em perceber o que em cada uma dessas experiências constitui seu(s) traço(s) singular(es), quais tipos de legibilidade para os acontecimentos são por elas propostos e quais efeitos de sentido podemos daí extrair.

Vinícius Andrade de Oliveira é doutorando em Comunicação Social pela UFMG e membro do grupo de pesquisa "Poéticas da Experiência". Participa de ações em audiovisual (seminários, produção de vídeos e curadorias) junto à Rede Coque Vive (PE).

viniciusandradedeoliveira@gmail.com

\section{Referências}

CESAR, A. "Ocupar, resistir, ressurgir". In: Catálogo do Forumdoc.bh. 2015. Belo Horizonte: Filmes de Quintal/FAFICH UFMG, 2015.

DIDI-HUBERMAN, G. "Imagem-montagem ou imagem-mentira". In: Imagens apesar de tudo. KKYM: Lisboa, 2012.

LINDEPERG, S.; COMOLLI, J. L. "Imagens de arquivos: imbricamento de olhares. Entrevista com Sylvie Lindeperg". In: Catálogo do Forumdoc.bh. 2010. Belo Horizonte: Filmes de Quintal/FAFICH UFMG, 2010.

LINDEPERG, S. "O caminho das imagens: três histórias de filmagens na primavera-verão de 1944". In: Estudos históricos, Rio de Janeiro, vol.26, número 51, 0-34, janeiro-junho de 2013.

MARICATO, E. O impasse da política urbana no Brasil. Petrópolis: Vozes, 2014.

MOVIMENTO PASSE LIVRE (São Paulo). "Não começou em Salvador, não vai terminar em São Paulo". In: MARICATO, E. et al. Cidades Rebeldes: Passe Livre as manifestações que tomaram as ruas do Brasil. São Paulo: Boitempo Editorial/Carta Maior, 2013.

ROLNIK, R. Guerra dos Lugares: a colonização da terra e da moradia na era das finanças. São Paulo: Boitempo, 2015.

SELIGMANN-SILVA, M. "O local do testemunho". In: Tempo e Argumento - Revista do Programa de Pós-graduação em História. Florianópolis: UDESC, v.2., n.1, jan/jun 2010, p. 3-20. 